\title{
TMSBr-mediated solvent- and work-up-free synthesis of a-2-deoxyglycosides from glycals
}

\author{
Mei-Yuan Hsu ${ }^{1,2,3}$, Yi-Pei Liu ${ }^{1,4}$, Sarah Lam ${ }^{1}$, Su-Ching Lin ${ }^{1}$ and Cheng-Chung Wang ${ }^{* 1,2}$
}

\author{
Full Research Paper \\ Address: \\ ${ }^{1}$ Institute of Chemistry, Academia Sinica, Taipei 115, Taiwan, \\ ${ }^{2}$ Chemical Biology and Molecular Biophysics Program, Taiwan \\ International Graduate Program, Academia Sinica, Taipei 115, \\ Taiwan, ${ }^{3}$ Department of Chemistry, National Taiwan University, Taipei \\ 106, Taiwan and ${ }^{4}$ Department of Chemistry, National Central \\ University, Jhongli 320, Taiwan \\ Email: \\ Cheng-Chung Wang ${ }^{*}$ - wangcc@chem.sinica.edu.tw \\ * Corresponding author \\ Keywords: \\ 2-deoxyglycosides; glycals; trimethylsilyl bromide (TMSBr); \\ triphenylphosphine oxide (TPPO) \\ Beilstein J. Org. Chem. 2016, 12, 1758-1764. \\ doi:10.3762/bjoc. 12.164 \\ Received: 08 April 2016 \\ Accepted: 09 July 2016 \\ Published: 04 August 2016 \\ Associate Editor: S. Flitsch \\ (c) 2016 Hsu et al.; licensee Beilstein-Institut. \\ License and terms: see end of document.
}

\section{Abstract}

The thio-additions of glycals were efficiently promoted by a stoichiometric amount of trimethylsilyl bromide (TMSBr) to produce $S$-2-deoxyglycosides under solvent-free conditions in good to excellent yields. In addition, with triphenylphosphine oxide as an additive, the TMSBr-mediated direct glycosylations of glycals with a large range of alcohols were highly $\alpha$-selective.

\section{Introduction}

Deoxyglycosides are essential moieties of numerous bioactive natural products, and are prevalent subunits in antitumor and antibiotic agents [1-3]. Furthermore, 2-deoxy- and 2,6dideoxyglycosides are crucial components for the pharmacology and bioactivity of many biologically active compounds [4], and were recently observed to inhibit cancer growth [5]. Because of the relevance of 2-deoxyglycosides, great efforts have been made in researching the assembly of oligosaccharides containing these sugars [6,7]. However, the absence of a neighbouring group at $\mathrm{C} 2$ causes poor stereoselectivity and high susceptibility to hydrolysis, which are the main obstacles to constructing glycosidic linkages stereoselectively [8]. Some approaches, such as the $\mathrm{AgPF}_{6}$-DTBMS [9] and preactivation ap- proach [10], can directly yield stereoselective glycosylations. Indirect methods that utilize auxiliary groups at $\mathrm{C} 2$, including halogen atoms [11-18], thio [19-21], and seleno groups [22-25], 1,2-migratory glycosylations that involve sulfur [26-33], oxygen [34], or nitrogen [35-37] atoms as directing groups and long-range directing functionalities at C6 [10,38-42] have also been developed to improve the stereoselectivity. However, additional required steps involving the introduction and removal of directing groups are reducing the efficiency.

Thioglycosides are some of the most commonly used donors for glycosylation reactions because of their high stability and reactivity [43]. Numerous stereoselective synthetic methods that use 
2-deoxythioglycosides have been reported [9,10,44-49]. We recently developed a glycosyl chloride-mediated synthesis of highly $\alpha$-selective 2 -deoxyglucosides by using 2 -deoxythioglucosides [50]. In the literature, to synthesize 2-deoxythioglycosides, a highly toxic tin hydride reagent was used to produce $S$-2-deoxysugars from glycosyl bromide through an anomeric glycosyl radical and acetate rearrangement, followed by subsequent thioglycosylation to afford 2-deoxythioglycosides as anomeric mixtures [10]. Glycals have been considered as alternative precursors for producing 2-deoxythioglycosides as well as oligosaccharides. Several methods based on the use of glycals in the presence of Lewis acids for $S$ - or $O$-2-deoxyglycoside preparations have been developed [51-63]. However, based on the hard and soft (Lewis) acids and bases (HSAB) theory, hard acids would coordinate to the harder $\mathrm{O} 3$ in glycals in preference to the softer alkene to initiate an undesired Ferrier rearrangement, leading to the formation of a considerable amount of 2,3-unsatuated glycosides. This constitutes the major competitive reaction pathway in acid-catalysed 2-deoxyglycosylation of glycals [52,57,59]. Besides, unfavourable conditions involving the use of expensive or toxic metal complexes, high temperatures, and long reaction times are usually required in most of the aforementioned methods.

Furthermore, organic solvents in laboratories are associated with numerous health hazards [64], and most of them are consumed during chemical reactions, work-up and purification procedures. Especially, dichloromethane, one of the most general solvents for glycosylation reactions, is acknowledged as an acute inhalation hazard and carcinogen $[65,66]$. To date, only a few studies of glycosylation under neat conditions have been published. In these methods either the need of heating [67-69] or the use of ball milling [70-72] was demanded. Moreover, the selectivity was manipulated by the neighbouring group effect on C2 [67,69-71], which is absent in 2-deoxyglycosides. Mild, work-up- and solvent-free reaction conditions for highly stereoselective 2-deoxyglycosylation is therefore desirable. Here, we present a solvent- and work-up-free approach to prepare $S$ - and $\alpha$-selective $O$-2-deoxyglycosides from glycals.

\section{Results and Discussion}

In our preliminary study, 77\% yield of 2-deoxythiolglucoside 2 was produced exclusively when glucal 1 in the presence of $p$-thiocresol was promoted by a stoichiometric amount of TMSBr under neat conditions at room temperature under ambient atmosphere (Table $1, \alpha: \beta=2: 1$, entry 1 ). Without work-up and washing, $S$-2-deoxyglycoside 2 could be directly isolated and purified by flash column chromatography. We further extended the scope of the reaction to other glycals by using TMSBr as the promoter under neat conditions (Table 1, entries 2-6). For per- $O$-benzylated glucal (3) and per- $O$-acety- lated rhamnal (5), the corresponding thiol-2-deoxyglycosides 7 $(61 \%, \alpha: \beta=2: 1)$ and $\mathbf{1 0}(76 \%, \alpha: \beta=2: 1)$ were produced in good yields with moderate stereoselectivity (Table 1 , entry 2 and 5). Interestingly, as shown in Table 1, entries 1 and 2, the inductive effect of the substituents played critical roles in their reactivity. Electron-withdrawing groups, but not electron-donating groups, in glycals were likely to enhance the reactivity. The effect of the donor conformation on the stereoselectivity of the glycosylation was probed by galactal 4 and fucal 6 . $S$-2-Deoxygalactoside $8(87 \%, \alpha: \beta=3: 1$, Table 1 , entry 3$)$ and $S$-2-deoxyfucoside $11(89 \%, \alpha: \beta=3: 1$, Table 1 , entry 6$)$ were produced in high yields with slightly superior selectivity. As shown in Table 1, entry 4, a prolonged reaction time led to further reaction of $\mathbf{8}$ to give $22 \%$ of a dithiol acetal side product 9 .

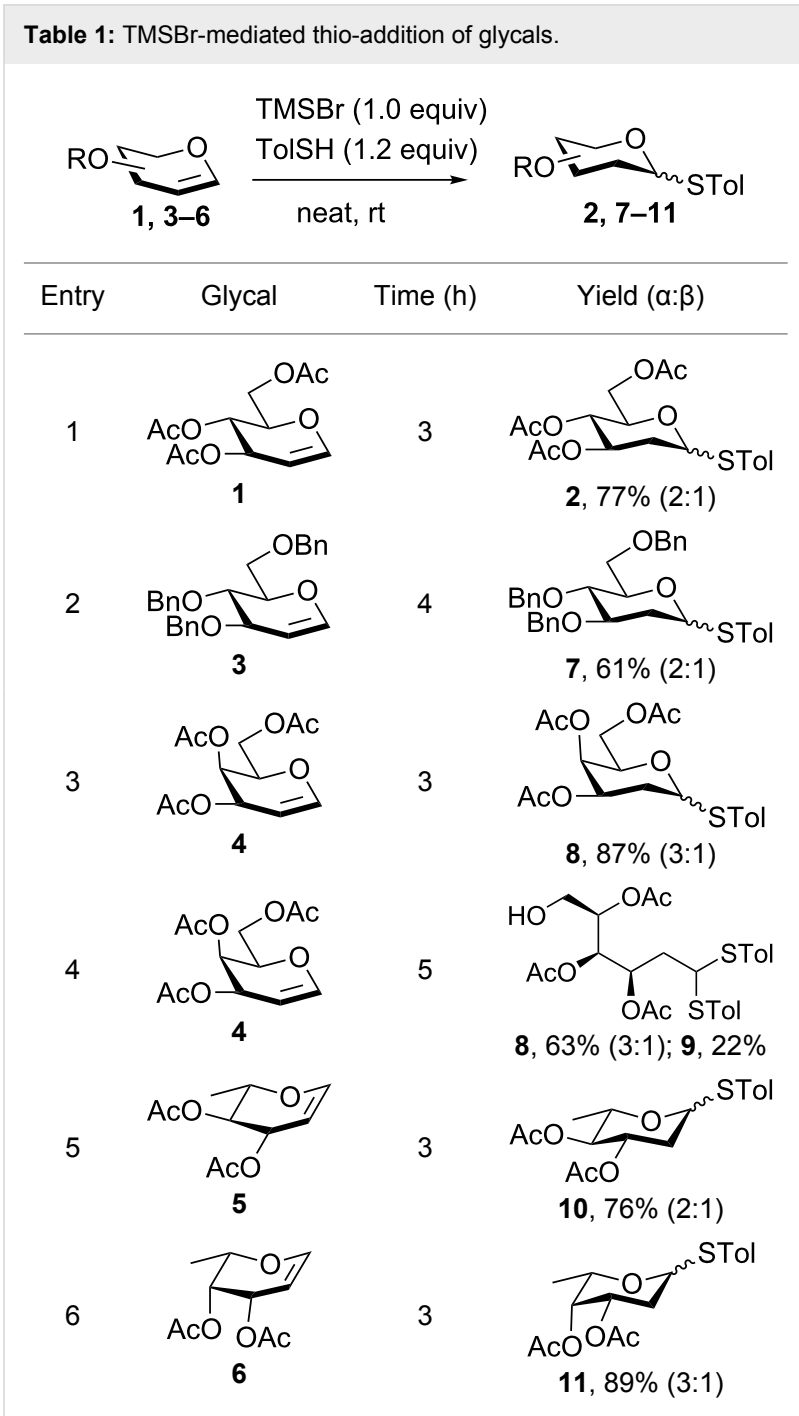

Inspired by the results obtained in the synthesis of $S$-2-deoxyglycosides, we explored the use of numerous alcohols as acceptors in order to directly synthesize $O-2$-deoxyglycosides from 
glycals. In Table 2 the reaction of glucal 1 and benzyl alcohol (12) under similar reaction conditions was tested and $O$-benzyl 2-deoxyglucoside 25 was produced in 59\% yield in the presence of TMSBr $(\alpha: \beta=3: 1$, Table 2, entry 1$)$. To further improve the $\alpha$-selectivity and the yield, various additives were screened (Table 2, entries 2-11) [73-77]. Several participating solvents, dimethylformamide (DMF) (64\%, Table 2, entry 2) [76], acetonitrile (ACN) [74] (44\%, Table 2, entry 3), tetrahydrofuran (THF) (56\%, Table 2, entry 4), and dioxane [75] (50\%, Table 2 , entry 5) were tested as glycosylation modulators and similar yields of $\mathbf{2 5}$ were obtained, but their $\alpha$-selectivities dramatically improved to $\alpha: \beta=10: 1$. In addition, 25 was afforded in $67 \%$ with excellent $\alpha$-selectivity ( $\alpha: \beta=10: 1$ ) with the addition of dimethyl sulfide (DMS) (Table 2, entry 6). However, the basic additive 2,4,6-tri-tert-butylpyridine (TTBP) produced 25 with poor selectivity ( $52 \%, \alpha: \beta=2: 1$, Table 2 , entry 7). Furthermore, various phosphine and phosphine oxide reagents were added in $O$-2-deoxyglycosylation reactions (Table 2, entries 8-11); surprisingly, the desired product $\mathbf{2 5}$ exhibited a high yield with excellent $\alpha$-selectivity (78\%, $\alpha: \beta=10: 1$, Table 2 , entry 11$)$ with TPPO [77].

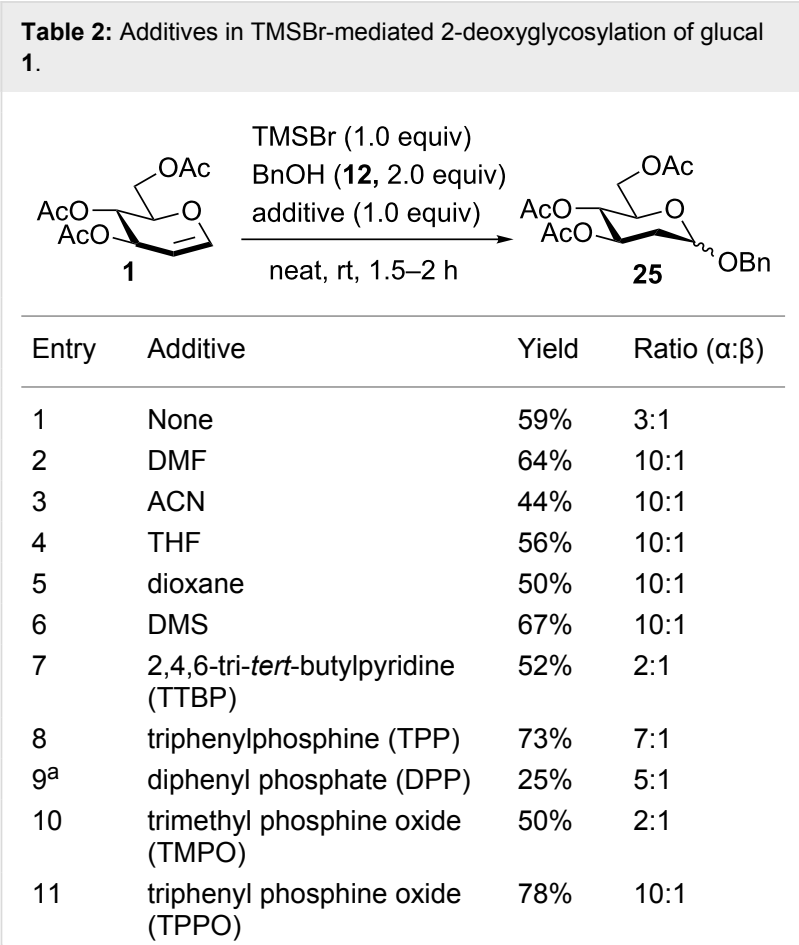

a 1 was recovered in $46 \%$.

Encouraged by these results, we attempted to extend the scope of the glycosylation of 3,4,6-O-acetyl- and $O$-benzylglucal ( 1 and 3) with other acceptors (Table 3). Under the optimized conditions, glucal 1 reacted with numerous primary, secondary, and tertiary alcohols, including methanol (13), allyl alcohol
(14), isopropanol (15), tert-butanol (16), 5-azidopentanol (17), cyclohexanol (18) and 2-adamantanol (19), to give $O$-2deoxyglucosides in high yields (74-90\%) and $\alpha$-selectivities ( $\alpha: \beta=7-10: 1$, Table 3, entries 2-8). Regarding the glycosylation with amino acid derivatives, L-serine $\mathbf{2 0}$ and threonine derivative 21, increased ratio of $\beta$-glucosides were formed in their corresponding products 33 (71\%, 5:1, Table 3, entry 9) and 34 (79\%, 4:1, Table 3, entry 10). For the use of monosaccharides as acceptors, primary monosaccharides $\mathbf{2 2}$ and $\mathbf{2 3}$ gave disaccharides 35 (80\%, Table 3, entry 11$)$ and 36 (78\%, Table 3 , entry 12$)$ respectively in high yields with moderate $\alpha$-selectivity ( $\alpha: \beta=4: 1)$. Surprisingly, in the glycosylation with secondary monosaccharide acceptor 24, $\alpha$-disaccharide 37 (56\%, Table 3, entry 13) was isolated as the sole product. For per- $O$ benzylated glucal 3, a higher yield of $\mathbf{3 8}(97 \%$, Table 3, entry 14) was produced with good selectivity $(\alpha: \beta=5: 1)$ in the presence of TPPO when compared to the additive-free conditions (79\%, Table 3, entry 15). For aliphatic alcohols (13-19), glycosylation products (39-45) were always obtained in excellent yields (75-95\%) and moderate selectivities $(\alpha: \beta=3-5: 1$, Table 3, entries 16-22). The reaction with amino acid residues 20 and 21 (Table 3, entries 23 and 24) produced aminosugars 46 $(68 \%, \alpha: \beta=5: 1)$ and $47(74 \%, \alpha: \beta=4: 1)$ in good yields with moderate $\alpha$-selectivity. Disaccharides $48(90 \%, \alpha: \beta=4: 1$, Table 3, entry 25$)$ and $\mathbf{4 9}(80 \%, \alpha: \beta=4: 1$, Table 3 , entry 26$)$ were formed in high yields with moderate selectivity similar to the examples of the products of primary monosaccharide acceptors 22 and 23. Finally, the secondary monosaccharide acceptor 24 (Table 3, entry 27) also underwent complete $\alpha$-selective glycosylation, producing $\alpha$-disaccharide $\mathbf{5 0}(67 \%)$ as the only product. According to our study, the glycosylation of per- $O$ acetylated glucal 1 with aliphatic alcohols 12-19 showed better $\alpha$-selectivities as compared to the per- $O$-benzylated glucal 3 . However, with amino acid derivatives $\mathbf{2 0}$ and $\mathbf{2 1}$ and monosaccharides 22-24 as acceptors, similar $\alpha$-selectivities were attained with both glucals $\mathbf{1}$ and $\mathbf{3}$.

The results using acetylated galactal 4 were summarized in Table 4. The reactions using several aliphatic alcohols (12, 14-18) as acceptors yielded the desired compounds $(\mathbf{5 1}, \mathbf{5 3}-\mathbf{5 7})$ in excellent yields $(90-99 \%)$ with high $\alpha$-selectivities $(\alpha: \beta=$ 7-9:1, Table 4, entries 1, 3-7). Glycosylation with $\mathrm{MeOH}(13)$; however, produced $\mathbf{5 2}$ in an excellent yield but lower selectivity $(95 \%, \alpha: \beta=4: 1$, Table 4 , entry 2$)$. The bulky acceptor 2-adamantanol (19) produced compound 58 in a decreased yield but with excellent selectivity because of its low solubility ( $43 \%$, $\alpha: \beta=13: 1$, Table 4 , entry 8 ). L-Serine and threonine derivatives 20 and 21 reacted with galactal $\mathbf{4}$ to give the glycosylated amino acids 59 and 60 (Table 4, entries 9 and 10) in excellent selectivities (59, $\alpha$ only; 60, $\alpha: \beta=9: 1)$ but in different yields (59, 50\%; 60, 97\%). In Table 4, entry 11, disaccharide 61 was 
Table 3: TMSBr-mediated 2-deoxyglycosylation of glucals 1 and $\mathbf{3}$.
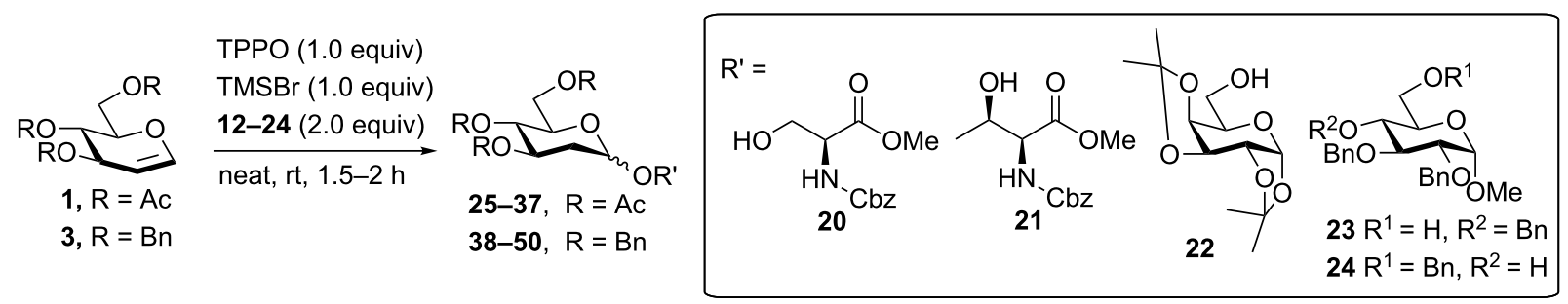

\begin{tabular}{|c|c|c|c|c|}
\hline Entry & Donor & Acceptor & Product & Yield ( $\alpha: \beta)$ \\
\hline 1 & 1 & benzyl alcohol (12) & 25 & $78 \%(10: 1)$ \\
\hline 2 & 1 & methanol (13) & 26 & $82 \%(10: 1)$ \\
\hline 3 & 1 & 3-propenol (14) & 27 & $78 \%(7: 1)$ \\
\hline 4 & 1 & isopropanol (15) & 28 & $74 \%(9: 1)$ \\
\hline 5 & 1 & tert-butanol (16) & 29 & $76 \%(8: 1)$ \\
\hline 6 & 1 & 5-azidopentanol (17) & 30 & $90 \%(10: 1)$ \\
\hline 7 & 1 & cyclohexanol (18) & 31 & $89 \%(10: 1)$ \\
\hline 8 & 1 & 2-adamantanol (19) & 32 & $86 \%(10: 1)$ \\
\hline $9^{a}$ & 1 & 20 & 33 & $71 \%(5: 1)$ \\
\hline $10^{\mathrm{a}}$ & 1 & 21 & 34 & $79 \%(4: 1)$ \\
\hline 11 & 1 & 22 & 35 & $80 \%(4: 1)$ \\
\hline $12^{\mathrm{a}}$ & 1 & 23 & 36 & $78 \%(4: 1)$ \\
\hline $13^{a}$ & 1 & 24 & 37 & $56 \%$ a only \\
\hline 14 & 3 & 12 & 38 & $97 \%(5: 1)$ \\
\hline $15^{b}$ & 3 & 12 & 38 & $79 \%(6: 1)$ \\
\hline 16 & 3 & 13 & 39 & $95 \%(4: 1)$ \\
\hline 17 & 3 & 14 & 40 & $91 \%(5: 1)$ \\
\hline 18 & 3 & 15 & 41 & $93 \%(5: 1)$ \\
\hline 19 & 3 & 16 & 42 & $85 \%(3: 1)$ \\
\hline 20 & 3 & 17 & 43 & $89 \%(5: 1)$ \\
\hline 21 & 3 & 18 & 44 & $81 \%(5: 1)$ \\
\hline 22 & 3 & 19 & 45 & $75 \%(5: 1)$ \\
\hline $23^{a}$ & 3 & 20 & 46 & $68 \%(5: 1)$ \\
\hline $24^{a}$ & 3 & 21 & 47 & $74 \%(4: 1)$ \\
\hline 25 & 3 & 22 & 48 & $90 \%(4: 1)$ \\
\hline $26^{a}$ & 3 & 23 & 49 & $80 \%(4: 1)$ \\
\hline $27^{a}$ & 3 & 24 & 50 & $67 \%$ a only \\
\hline
\end{tabular}

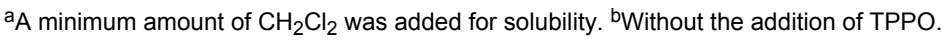

acquired in the presence of $\mathbf{2 2}$ with a moderate yield and selectivity $(50 \%, \alpha: \beta=4: 1)$. When primary monosaccharide 23 was used as the acceptor, disaccharide $\mathbf{6 2}$ was provided in an excellent yield and selectivity $(94 \%, \alpha: \beta=10: 1$, Table 4 , entry 12$)$. Additionally, a $60 \%$ yield of the $\alpha$-only product 63 was observed exclusively when the secondary hydroxyl glucoside $\mathbf{2 4}$ was used (Table 4, entry 13). Notably, the disubstituted side product was not observed in this reaction.

On the basis of these results, we demonstrated the applicability of the methodology in oligosaccharide synthesis by synthesising trisaccharide 66 in two sequential steps (Scheme 1).
Monosaccharide acceptor 64 underwent the TMSBr-mediated nucleophilic addition to glucal 1 to produce exclusively disaccharide $65(97 \%, \alpha: \beta=7: 1)$ in an excellent yield with high $\alpha$-selectivity. Remarkably, the 1-thiol group remained intact after the formation of disaccharide $\mathbf{6 5}$. Subsequently, 65 was coupled with the primary hydroxy saccharide acceptor $\mathbf{2 3}$ through a chloride-mediated preactivation glycosylation to afford 66 in $71 \%$ yield with moderate selectivity $(\alpha: \beta=1: 2)$ [16].

Two possible mechanisms are proposed for the $\alpha$-selectivity observed here (Scheme 2). It is well-accepted that the acid-cata- 


\begin{tabular}{|llll}
\hline Table 4: TMSBr-mediated 2-deoxyglycosylation of O-acetyl galactal $\mathbf{4}$. \\
\hline
\end{tabular}

aA minimum amount of $\mathrm{CH}_{2} \mathrm{Cl}_{2}$ was added for solubility.

lysed nucleophilic addition of an alcohol to a glycal is likely to proceed through the formation of an oxocarbenium ion via the protonation at $\mathrm{C} 2[6,63]$. In the presence of TPPO, the oxocarbenium cation is stabilized by the ion-dipole interaction with TPPO oriented preferably at the pseudoequatorial position [78] and the ensuing $\mathrm{S}_{\mathrm{N}}$ 2-like displacement by the alcohol contributes to the improvement of the $\alpha$-selectivity (Scheme 2, route A). Alternatively, it is possible that a 2-deoxyglycosyl bromide is first generated mainly in the more stable $\alpha$-form [61]. The

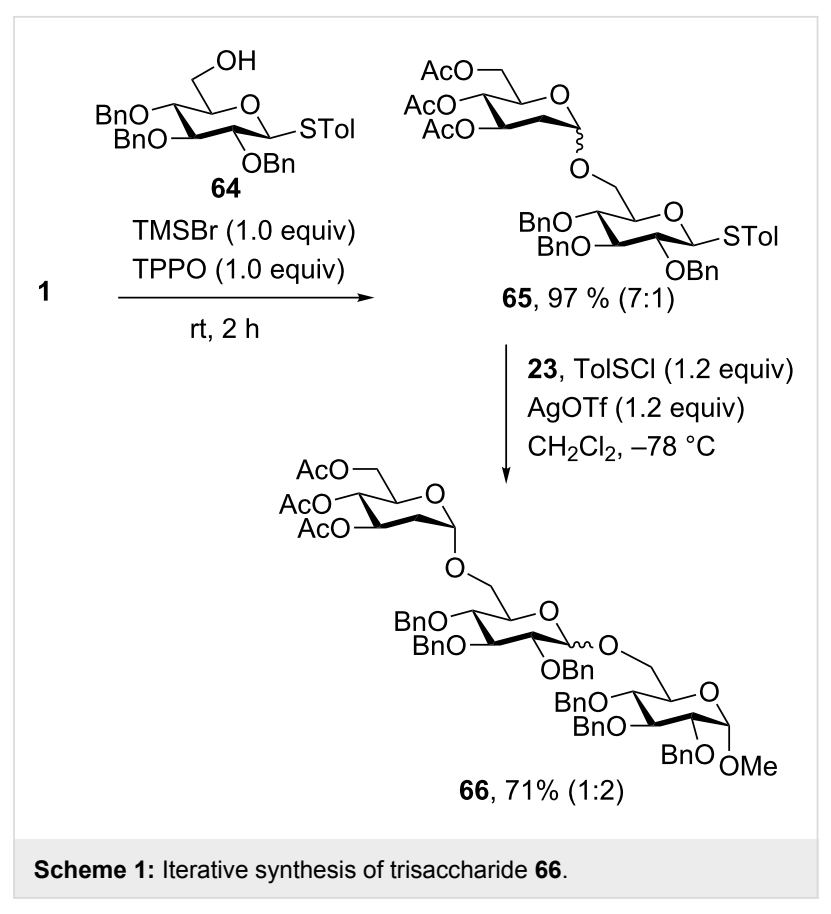

glycosyl bromide intermediate then undergoes double $\mathrm{S}_{\mathrm{N}}$ 2-like substitution by TPPO and the alcohol to give the $\alpha$-glycoside as the major product [77] (Scheme 2, route B).

\section{Conclusion}

A simple, efficient, and environmentally friendly method for preparing $S$ - and $O$-2-deoxyglycosides was established. $S$-2Deoxyglycosides were obtained with moderate $\alpha$-selectivity when glycals and thiocresol were treated with a stoichiometric amount of TMSBr in neat conditions. Extension of this approach to hydroxy acceptors provided an efficient method to construct the glycosyl bonds between the 2-deoxysugars and the

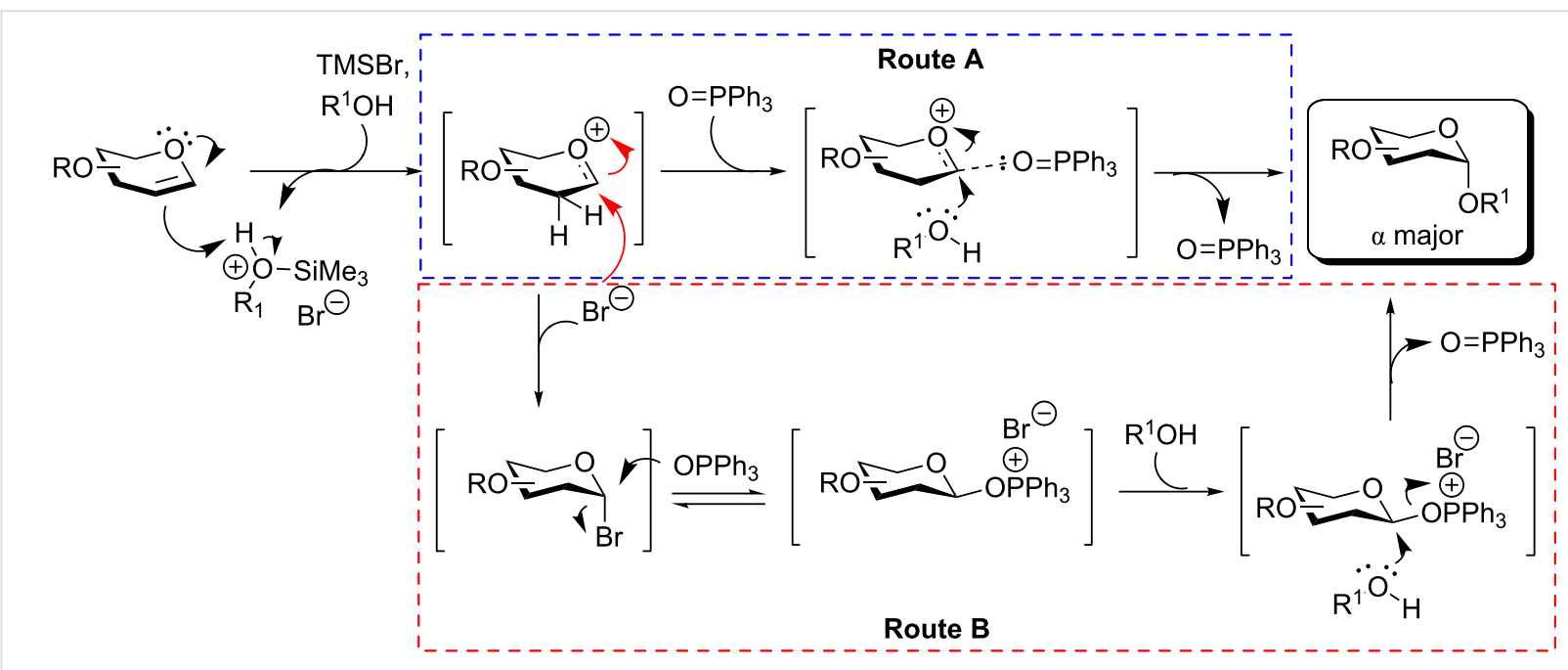

Scheme 2: Proposed mechanisms for TMSBr-mediated synthesis of 2-deoxyglycosides in the presence of TPPO. 
acceptors in good to excellent yields with high $\alpha$-selectivity in the presence of TPPO, which served as an additive that improved both glycosylation yield and $\alpha$-selectivity. Without the use of excess solvents, toxic reagents, special equipment, and high temperature, reactions were complete in a few hours at room temperature under ambient atmosphere. Ferrier rearranged products and other side products were not observed. As these reactions were clean, tedious work-up and extraction processes could be obviated prior to purification by flash column chromatography. The utility of this glycosylation method was highlighted by an iterative synthesis of trisaccharide $\mathbf{6 6}$.

\section{Supporting Information}

\section{Supporting Information File 1}

Detailed experimental procedures, compound characterization data, and copies of NMR spectra. [http://www.beilstein-journals.org/bjoc/content/ supplementary/1860-5397-12-164-S1.pdf]

\section{Acknowledgements}

This work was supported by the Ministry of Science and Technology of Taiwan (MOST 103-2113-M-001-022-; MOST 1042113-M-001-003-) and Academia Sinica. We thank Mr. Joost Vercruysse for proofreading this manuscript.

\section{References}

1. Langenhan, J. M.; Peters, N. R.; Guzei, I. A.; Hoffmann, M.; Thorson, J. S. Proc. Natl. Acad. Sci. U. S. A. 2005, 102, 12305-12310. doi:10.1073/pnas.0503270102

2. Daniel, P. T.; Koert, U.; Schuppan, J. Angew. Chem., Int. Ed. 2006, 45, 872-893. doi:10.1002/anie.200502698 Angew. Chem. 2006, 118, 886-908. doi:10.1002/ange.200502698

3. Iyer, A. K. V.; Zhou, M.; Azad, N.; Elbaz, H.; Wang, L.; Rogalsky, D. K.; Rojanasakul, Y.; O'Doherty, G. A.; Langenhan, J. M. ACS Med. Chem. Lett. 2010, 1, 326-330. doi:10.1021/ml1000933

4. Nicolaou, K. C.; Mitchel, H. J. Angew. Chem., Int. Ed. 2001, 40, 1576-1624. doi:10.1002/1521-3773(20010504)40:9<1576::AID-ANIE15760>3.0.CO ;2-G

5. Xi, H.; Kurtoglu, M.; Lampidis, T. J. IUBMB Life 2014, 66, 110-121. doi:10.1002/iub.1251

6. Hou, D.; Lowary, T. L. Carbohydr. Res. 2009, 344, 1911-1940. doi:10.1016/j.carres.2009.07.013

7. Marzabadi, C. H.; Franck, R. W. Tetrahedron 2000, 56, 8385-8417. doi:10.1016/S0040-4020(00)00691-8

8. Overend, W. G.; Rees, C. W.; Sequeira, J. S. J. Chem. Soc. 1962, 3429-3440. doi:10.1039/jr9620003429

9. Lear, M. J.; Yoshimura, F.; Hirama, M. Angew. Chem., Int. Ed. 2001, 40, 946-949. doi:10.1002/1521-3773(20010302)40:5<946::AID-ANIE946>3.0.CO;2G

10. Lu, Y.-S.; Li, Q.; Zhang, L.-H.; Ye, X.-S. Org. Lett. 2008, 10, 3445-3448. doi:10.1021/ol801190c
11. Roush, W. R.; Briner, K.; Sebesta, D. P. Synlett 1993, 264-266. doi:10.1055/s-1993-22425

12. Roush, W. R.; Bennett, C. E. J. Am. Chem. Soc. 1999, 121, 3541-3542. doi:10.1021/ja984365j

13. Roush, W. R.; Gung, B. W.; Bennett, C. E. Org. Lett. 1999, 1, 891-893. doi:10.1021/ol9908070

14. Tatsuta, K.; Fujimoto, K.; Kinoshita, M.; Umezawa, S. Carbohydr. Res. 1977, 54, 85-104. doi:10.1016/S0008-6215(00)80558-3

15. Thiem, J.; Gerken, M. J. Org. Chem. 1985, 50, 954-958. doi:10.1021/jo00207a009

16. Thiem, J.; Schöttmer, B. Angew. Chem., Int. Ed. Engl. 1987, 26, 555-557. doi:10.1002/anie.198705551 Angew. Chem. 1987, 99, 591-592. doi:10.1002/ange.19870990626

17. Bucher, C.; Gilmour, R. Angew. Chem., Int. Ed. 2010, 49, 8724-8728. doi:10.1002/anie.201004467 Angew. Chem. 2010, 122, 8906-8910. doi:10.1002/ange.201004467

18. Durantie, E.; Bucher, C.; Gilmour, R. Chem. - Eur. J. 2012, 18, 8208-8215. doi:10.1002/chem.201200468

19. Ito, Y.; Ogawa, T. Tetrahedron Lett. 1987, 28, 2723-2726. doi:10.1016/S0040-4039(00)96191-4

20. Grewal, G.; Kaila, N.; Franck, R. W. J. Org. Chem. 1992, 57, 2084-2092. doi:10.1021/jo00033a033

21. Ramesh, S.; Franck, R. W. J. Chem. Soc., Chem. Commun. 1989, 960-962. doi:10.1039/C39890000960

22. Barrett, A. G. M.; Miller, T. A. Tetrahedron Lett. 1988, 29, 1873-1874. doi:10.1016/S0040-4039(00)82065-1

23. Perez, M.; Beau, J.-M. Tetrahedron Lett. 1989, 30, 75-78. doi:10.1016/S0040-4039(01)80327-0

24. Sebesta, D. P.; Roush, W. R. J. Org. Chem. 1992, 57, 4799-4802. doi:10.1021/jo00044a010

25. Nicolaou, K. C.; Pastor, J.; Barluenga, S.; Winssinger, N. Chem. Commun. 1998, 1947-1948. doi:10.1039/a804795b

26. Auzanneau, F.-I.; Bundle, D. R. Carbohydr. Res. 1991, 212, 13-24. doi:10.1016/0008-6215(91)84041-C

27. Zuurmond, H. M.; van der Klein, P. A. M.; van der Marel, G. A.; van Boom, J. H. Tetrahedron 1993, 49, 6501-6514. doi:10.1016/S0040-4020(01)80165-4

28. Yang, Z.; Yu, B. Carbohydr. Res. 2001, 333, 105-114 doi:10.1016/S0008-6215(01)00124-0

29. Yu, B.; Yang, Z. Org. Lett. 2001, 3, 377-379. doi:10.1021/ol006894+ 30. Sajtos, F.; Lázár, L.; Borbás, A.; Bajza, I.; Lipták, A. Tetrahedron Lett. 2005, 46, 5191-5194. doi:10.1016/j.tetlet.2005.05.112

31. Lázár, L.; Bajza, I.; Jakab, Z.; Lipták, A. Synlett 2005, 2242-2244. doi:10.1055/s-2005-872244

32. Hou, D.; Lowary, T. L. Org. Lett. 2007, 9, 4487-4490. doi:10.1021/ol7019108

33. Hou, D.; Lowary, T. L. J. Org. Chem. 2009, 74, 2278-2289. doi:10.1021/jo900131a

34. Capozzi, G.; Dios, A.; Franck, R. W.; Geer, A.; Marzabadi, C.; Menichetti, S. C.; Tamarez, M. Angew. Chem. 1996, 108, 805-807. doi:10.1002/ange.19961080710

Angew. Chem. Int. Ed. Engl. 1996, 35, 777-779. doi:10.1002/anie.199607771

35. Gurjar, M. K.; Ghosh, P. K. Indian J. Chem. 1988, 27B, 1063-1064.

36. Trumtel, M.; Veyrières, A.; Sinay, P. Tetrahedron Lett. 1989, 30, 2529-2532. doi:10.1016/S0040-4039(01)80442-1

37. Castro-Palomino, J. C.; Schmidt, R. R. Synlett 1998, 501-503. doi:10.1055/s-1998-1689

38. Pongdee, R.; Wu, B.; Sulikowski, G. A. Org. Lett. 2001, 3, 3523-3525. doi:10.1021/ol016593f 
39. Crich, D.; Vinogradova, O. J. Org. Chem. 2006, 71, 8473-8480. doi:10.1021/jo061417b

40. Kim, K. S.; Park, J.; Lee, Y. J.; Seo, Y. S. Angew. Chem., Int. Ed. 2003, 42, 459-462. doi:10.1002/anie.200390139

Angew. Chem. 2003, 115, 475-478. doi:10.1002/ange.200390107

41. Park, J.; Boltje, T. J.; Boons, G.-J. Org. Lett. 2008, 10, 4367-4370. doi:10.1021/ol801833n

42. Lu, Y.-S.; Li, Q.; Wang, Y.; Ye, X.-S. Synlett 2010, 1519-1524 doi:10.1055/s-0029-1219943

43. Codée, J. D. C.; Litjens, R. E. J. N.; van den Bos, L. J.; Overkleeft, H. S.; van der Marel, G. A. Chem. Soc. Rev. 2005, 34, 769-782. doi:10.1039/b417138c

44. Zhang, G.; Fang, L.; Zhu, L.; Aimiuwu, J. E.; Shen, J.; Cheng, H.; Muller, M. T.; Lee, G. E.; Sun, D.; Wang, P. G. J. Med. Chem. 2005, 48, 5269-5278. doi:10.1021/jm050144u

45. Zhang, G.; Fang, L.; Zhu, L.; Zhong, Y.; Wang, P. G.; Sun, D. J. Med. Chem. 2006, 49, 1792-1799. doi:10.1021/jm050916m

46. Fan, E.; Shi, W.; Lowary, T. L. J. Org. Chem. 2007, 72, 2917-2928. doi:10.1021/jo062542q

47. Paul, S.; Jayaraman, N. Carbohydr. Res. 2007, 342, 1305-1314. doi:10.1016/j.carres.2007.02.030

48. Braccini, I.; Derouet, C.; Esnault, J.; de Penhoat, C. H.; Mallet, J.-M.; Michon, V.; Sinay, P. Carbohydr. Res. 1993, 246, 23-41. doi:10.1016/0008-6215(93)84021-W

49. Jaunzems, J.; Sourkouni-Argirusi, G.; Jesberger, M.; Kirschning, A. Tetrahedron Lett. 2003, 44, 637-639. doi:10.1016/S0040-4039(02)02708-9

50. Verma, V. P.; Wang, C.-C. Chem. - Eur. J. 2013, 19, 846-851. doi:10.1002/chem.201203418

51. Beau, J.-M.; Sinay, P. Tetrahedron Lett. 1985, 26, 6185-6188. doi:10.1016/S0040-4039(00)95048-2

52. Bolitt, V.; Mioskowski, C.; Lee, S.-G.; Falck, J. R. J. Org. Chem. 1990, 55, 5812-5813. doi:10.1021/jo00310a006

53. Mereyala, H. B.; Ravi, D. Tetrahedron Lett. 1991, 32, 7317-7320. doi:10.1016/0040-4039(91)80508-4

54. Yadav, J. S.; Reddy, B. V. S.; Reddy, K. B.; Satyanarayana, M. Tetrahedron Lett. 2002, 43, 7009-7012. doi:10.1016/S0040-4039(02)01584-8

55. Paul, S.; Jayaraman, N. Carbohydr. Res. 2004, 339, 2197-2204. doi:10.1016/j.carres.2004.07.010

56. Sherry, B. D.; Loy, R. N.; Toste, F. D. J. Am. Chem. Soc. 2004, 126, 4510-4511. doi:10.1021/ja031895t

57. Palmier, S.; Vauzeilles, B.; Beau, J.-M. Org. Biomol. Chem. 2003, 1, 1097-1098. doi:10.1039/b301805a

58. Yadav, J. S.; Reddy, B. V. S.; Bhasker, E. V.; Raghavendra, S.; Narsaiah, A. V. Tetrahedron Lett. 2007, 48, 677-680. doi:10.1016/j.tetlet.2006.11.103

59. Lin, H.-C.; Pan, J.-F.; Chen, Y.-B.; Lin, Z.-P.; Lin, C.-H. Tetrahedron 2011, 67, 6362-6368. doi:10.1016/j.tet.2011.05.124

60. Balmond, E. I.; Coe, D. M.; Galan, M. C.; McGarrigle, E. M. Angew. Chem., Int. Ed. 2012, 51, 9152-9155. doi:10.1002/anie.201204505

61. Cui, X.-K.; Zhong, M.; Meng, X.-B.; Li, Z.-J. Carbohydr. Res. 2012, 358, 19-22. doi:10.1016/j.carres.2012.06.004

62. Balmond, E. I.; Benito-Alifonso, D.; Coe, D. M.; Alder, R. W.; McGarrigle, E. M.; Galan, M. C. Angew. Chem., Int. Ed. 2014, 53, 8190-8194. doi:10.1002/anie.201403543

63. Kimura, T.; Takahashi, D.; Toshima, K. J. Org. Chem. 2015, 80, 9552-9562. doi:10.1021/acs.joc.5b01542
64. Dick, F. D. Occup. Environ. Med. 2006, 63, 221-226. doi:10.1136/oem.2005.022400

65. Rioux, J. P.; Myers, R. A. M. J. Emerg. Med. 1988, 6, 227-238. doi:10.1016/0736-4679(88)90330-7

66. Lefevre, P. A.; Ashby, J. Carcinogenesis 1989, 10, 1067-1072. doi:10.1093/carcin/10.6.1067

67. Limousin, C.; Cléophax, J.; Petit, A.; Loupy, A.; Lukacs, G. J. Carbohydr. Chem. 1997, 16, 327-342. doi:10.1080/07328309708006533

68. de Oliveira, R. N.; de Freitas Filho, J. R.; Srivastava, R. M. Tetrahedron Lett. 2002, 43, 2141-2143. doi:10.1016/S0040-4039(02)00156-9

69. Lautrette, S.; Granet, R.; Krausz, P. Chem. Commun. 2004, 586-587. doi:10.1039/b315699k

70. Patil, P. R.; Kartha, K. P. R. J. Carbohydr. Chem. 2008, 27, 411-419. doi:10.1080/07328300802402259

71. Tyagi, M.; Khurana, D.; Kartha, K. P. R. Carbohydr. Res. 2013, 379, 55-59. doi:10.1016/j.carres.2013.06.018

72. Kumar, V.; Yadav, N.; Kartha, K. P. R. Carbohydr. Res. 2014, 397, 18-26. doi:10.1016/j.carres.2014.08.002

73. Crich, D.; Smith, M.; Yao, Q.; Picione, J. Synthesis 2001, 323-326. doi:10.1055/s-2001-10798

74. Lemieux, R. U.; Ratclffe, R. M. Can. J. Chem. 1979, 57, 1244-1251. doi:10.1139/v79-203

75. Satoh, H.; Hansen, H. S.; Manabe, S.; van Gunsteren, W. F.; Hünenberger, P. H. J. Chem. Theory Comput. 2010, 6, 1783-1797. doi:10.1021/ct1001347

76. Chen, J.-H.; Ruei, J.-H.; Mong, K.-K. T. Eur. J. Org. Chem. 2014, 1827-1831. doi:10.1002/ejoc.201400006

77. Oka, N.; Kajino, R.; Takeuchi, K.; Nagakawa, H.; Ando, K. J. Org. Chem. 2014, 79, 7656-7664. doi:10.1021/jo500632h

78. Bogusiak, J.; Szeja, W. Synlett 1997, 661-662. doi:10.1055/s-1997-3245

\section{License and Terms}

This is an Open Access article under the terms of the Creative Commons Attribution License (http://creativecommons.org/licenses/by/2.0), which permits unrestricted use, distribution, and reproduction in any medium, provided the original work is properly cited.

The license is subject to the Beilstein Journal of Organic Chemistry terms and conditions:

(http://www.beilstein-journals.org/bjoc)

The definitive version of this article is the electronic one which can be found at: doi:10.3762/bjoc. 12.164 